\title{
Activation of non-ischemic, hypoxia-inducible signalling pathways up-regulate cytoprotective genes in the murine liver ${ }^{\text {th }}$
}

\author{
Jan Plock ${ }^{1}$, Steffen Frese ${ }^{2}$, Adrian Keogh ${ }^{1}$, Sonja Bisch-Knaden ${ }^{1}$, Erick Ayuni ${ }^{1}$, \\ Nadia Corazza ${ }^{5}$, Christian Weikert ${ }^{3}$, Stephan Jakob ${ }^{3}$, Dominique Erni ${ }^{4}$, \\ Jean-François Dufour ${ }^{6}$, Thomas Brunner ${ }^{5}$, Daniel Candinas ${ }^{1}$, Deborah Stroka ${ }^{1, *}$ \\ ${ }^{1}$ Clinic of Visceral and Transplantation Surgery, Department of Clinical Research, University of Bern, Murtenstrase 35, 3010 Bern, Switzerland \\ ${ }^{2}$ Thoracic Surgery, Department of Clinical Research, University of Bern, Murtenstrase 35, 3010 Bern, Switzerland \\ ${ }^{3}$ Intensive Care Medicine, Department of Clinical Research, University of Bern, Murtenstrase 35, 3010 Bern, Switzerland \\ ${ }^{4}$ Department of Plastic Surgery, Department of Clinical Research, University of Bern, Murtenstrase 35, 3010 Bern, Switzerland \\ ${ }^{5}$ Institute of Pathology, University of Bern, Murtenstrase 35, 3010 Bern, Switzerland \\ ${ }^{6}$ Institute of Clinical Pharmacology, University of Bern, Murtenstrase 35, 3010 Bern, Switzerland
}

Background/Aims: We investigated the molecular response of a non-ischemic hypoxic stress in the liver, in particular, to distinguish its hepatoprotective potential.

Methods: The livers of mice were subjected to non-ischemic hypoxia by clamping the hepatic-artery (HA) for 2 h while maintaining portal circulation. Hypoxia was defined by a decrease in oxygen saturation, the activation of hypoxia-inducible factor (HIF)-1 and the mRNA up-regulation of responsive genes. To demonstrate that the molecular response to hypoxia may in part be hepatoprotective, pre-conditioned animals were injected with an antibody against Fas (Jo2) to induce acute liver failure. Hepatocyte apoptosis was monitored by caspase-3 activity, cleavage of lamin A and animal survival.

Results: Clamping the HA induced a hypoxic stress in the liver in the absence of severe metabolic distress or tissue damage. The hypoxic stimulus was sufficient to activate the HIF-1 signalling pathway and up-regulate hepatoprotective genes. Pre-conditioning the liver with hypoxia was able to delay the onset of Fas-mediated apoptosis and prolong animal survival.

Conclusions: Our data reveal that hepatic cells can sense and respond to a decrease in tissue oxygenation, and furthermore, that activation of hypoxia-inducible signalling pathways function in part to promote liver cell survival.

Keywords: Liver; Hypoxia; Mouse; Hepatoprotective genes; Hypoxia-inducible factor-1

\footnotetext{
Associate Editor: A. Geerts

The authors declare that they have nothing to disclose regarding funding or conflict of interest with respect to this manuscript.

* Corresponding author. Tel.: +41 31632 2748; fax: +41 31382 4508.

E mail address: deborah.stroka@insel.ch (D. Stroka).

Abbreviations: HIF, hypoxia inducible factor; IGFBP, insulin like growth factor binding protein; HO, heme oxygenase; HA, hepatic artery; Epo, erythropoietin; VEGF, vascular endothelial cell growth factor; HGF, hepatocyte growth factor.
}

\section{Introduction}

In the liver, a physiologically oxygen gradient is created as a result of unidirectional blood flow and is a major regulator of gene expression and for the liver's metabolic zonation [1]. Often under both physiological and pathological conditions, the supply of oxygen can be insufficient to sustain the liver's highly active, metabolic and synthetic functions [1,2]. When the duration or the severity of oxygen deprivation exceeds critical levels the cells will be irreversibly damaged, however under low but physiologically relevant oxygen levels (hypoxia) cells are able to adapt and to survive. 
Among the adaptive responses to cellular hypoxia is the activation of oxygen-sensitive transcription factors [3]. The most extensively studied is hypoxia-inducible factor, HIF-1. HIF-1 is regulated via the oxygen-dependent degradation of its $\alpha$-subunit [4 6]. In the presence of molecular oxygen, hydroxylation of specific prolyl residues generates a binding site for a ubiquitin ligase complex which contains the von Hippel-Lindau (VHL) tumour suppressor protein. Binding of this complex results in its degradation $[7$ 11]. Under hypoxic conditions, HIF- $1 \alpha$ protein is stabilized and is translocated to the nucleus, where together with HIF-1 $\beta$ and transcription co-activators, it activates its target genes (reviewed in [12]). HIF-1 is considered to be the major regulator of more than 100 physiologically important genes whose function are mainly to protect against tissue damage and cell death and to help restore oxygen homeostasis. Therapeutic strategies of targeting the HIF pathway are twofold. Inhibition of HIF signalling is attractive in the context of tumour biology, in which hypoxia promotes growth and invasion of tumour cells and accounts for an increased resistance to anticancer therapies. On the other hand, activation of the HIF pathway is being developed clinically for the treatment of conditions associated with tissue injury or damage particularly in the brain (stroke), heart (myocardial infarction) and kidney (acute renal failure). Interestingly, in the liver several proteins that are regulated by hypoxia and HIF-1 are also part of the growth factor and cytokine pathways involved in liver regeneration and hepatoprotection [13 19].

In this study we established a model of non-ischemic, hypoxic stress in order to investigate the molecular response to localized hypoxia in a normal, healthy mouse liver in vivo. Taking advantage of the liver's dual blood supply, the hepatic artery (HA) was clamped to remove the supply of arterial blood, while the poorly oxygenated blood from portal circulation was maintained. First we determined if depleting the well-oxygenated blood from the HA would result in a hypoxic stress. Next, we verified that this stress was sufficient to activate a hypoxia-driven molecular response, namely activation of the HIF-1 signalling pathway. And finally we tested whether the hypoxia-induced response functions as part of a protective response, and thereby delays the onset of Fas-mediated apoptosis.

\section{Materials and methods}

\subsection{Surgical animal models}

This study was performed in accordance with the National Institute of Health's Guidelines for the Care and Use of Laboratory Animals and with the approval of the local Animal Ethics Committee. Six week old male Balb/C mice were anesthetized with an intraperitoneal injection of Dormitor ${ }^{\circledR}(500 \mu \mathrm{g} / \mathrm{kg})$, Climasol ${ }^{\circledR}(5 \mathrm{mg} / \mathrm{kg})$ and Fentanyl $(50 \mu \mathrm{g} /$ kg) (Dr. Graub, Bern, CH). Microdialysis catheters (CMA/20; CMA Microdialysis AB, Stockholm, Sweden) were introduced into the med ian and left liver lobe. After a $1 \mathrm{~h}$ stabilization period, a baseline sam ple was taken. Using microvascular surgical clips either the main HA (hypoxia) or the portal triad in the left liver lobe (anoxia) was clamped for $2 \mathrm{~h}$. Samples for microdialysis were taken every $30 \mathrm{~min}$ during the 2 hour clamping period. Also, the tissue level of saturated oxygen was monitored every $30 \mathrm{~min}$ using an $\mathrm{O} 2 \mathrm{C}$ surface probe $(\mathrm{O} 2 \mathrm{C}$, LEA Med izintechnik, Germany). Unclamped livers of mice served as sham con trols. Thirty minutes before the end of the experiment an intraperitoneal injection of HypoxyProbe ${ }^{\mathrm{TM}} 1[(60 \mathrm{mg} / \mathrm{kg}$ of body weight) Chemicon, Germany) was administered. At the end point, the liver was removed taking care to avoid re oxygenation of the tissue.

\subsection{Fas-mediated hepatotoxicity}

In preliminary experiments, the optimal dose of the anti Fas anti body (Jo2; BD Biosciences Pharmingen) administered was determined to be $0.2 \mathrm{mg} / \mathrm{kg}$ of body weight. At this level, Jo2 induced severe signs of apoptosis within $2 \mathrm{~h}$. To ensure that its access to the liver was unim paired, full blood flow was reinstated prior to its injection into the tail vein. Mice were either sacrificed $2 \mathrm{~h}$ later for the biochemical analysis of cell damage and apoptosis or observed for survival.

\subsection{Histology and immunohistochemistry}

Formalin fixed, paraffin embedded tissues were cut into five $\mu \mathrm{m}$ thick sections and mounted on SuperFrost Plus slides (Roth). For his tological analysis, sections were re hydrated and stained with $1 \%$ eosin Y and Mayer's hematoxylin (Sigma). For the detection of Hyp oxyprobe $^{T M}$, the sections were initially treated with $3 \%$ hydrogen perox ide for $5 \mathrm{~min}$ at room temperature to block endogenous peroxidase activity, and then with $0.01 \%$ pronase (Sigma) for 40 min at $40{ }^{\circ} \mathrm{C}$ for antigen retrieval. Thereafter, the sections were treated with Dako blocking solution (Dako) for $5 \mathrm{~min}$, with the Hypoxyprobe 1 antibody [diluted 1:50 (Chemicon)] for $40 \mathrm{~min}$, with biotin conjugated $\mathrm{F}(\mathrm{ab})_{2}$ [diluted 1:500 (Jackson ImmunoResearch Europe)] for $20 \mathrm{~min}$, and with streptavidin peroxidase for $20 \mathrm{~min}$. Between each treatment step, the sections were thoroughly rinsed with $0.2 \%$ Brij 35 (Applichem) in phosphate buffered saline. The immunosignal was developed with the peroxidase chromagen DAB (Sigma). For the detection of lamin A, the sections were initially treated with $10 \mathrm{mM}$ citrate for $35 \mathrm{~min}$ in a microwave oven (for antigen retrieval) and then with $3 \%$ hydrogen peroxide for $5 \mathrm{~min}$ at room temperature (to block endogenous perox idase activity). Thereafter, they were incubated with an anti antibody against cleaved lamin A [diluted 1:1000 (Cell Signaling)] in Tris buf fered saline containing $0.5 \%$ bovine serum albumin for $3 \mathrm{~h}$. The immu nosignal was detected using the PicTure Plus kit (Zymed). For detection of A20, sections were pressure cooked for 10 min in Antigen Retrieval Citrate Buffer (Dako) and blocked for 15 min with serum free protein block (Dako). Monoclonal anti A20 antibody (Stressgen Bioreagents) was biotinylated according to Animal Research Kit (ARK) (Dako) and incubated overnight. Signals were detected using a streptavidin peroxidase (ARK: Dako) and developed with DAB (Sigma). All sections were counterstained with haematoxylin and examined using a Leica DMRB microscope equipped with IM50 Leica imaging software (Leica Microsystems, Glattbrugg, $\mathrm{CH}$ ).

\subsection{Microdialysis}

Interstitial concentrations of glycerol, lactate and pyruvate were assessed by microdialysis, as previously described [20], using CMA 20 microdialysis catheters and the CMA 600 analysis system (CMA Microdialysis AB, Stockholm, Sweden).

\subsection{Western blotting}

Nuclear proteins (HIF $1 \alpha$ ) or total protein (HO 1) were extracted from hepatic tissue and quantified using the Bradford assay (Bio Rad). Equal amounts of protein $(50 \mu \mathrm{g})$ were separated by 
SDS PAGE and transferred to nitrocellulose membranes (Bio Rad). Membranes were incubated overnight at $4{ }^{\circ} \mathrm{C}$ with a chicken poly clonal anti HIF $1 \alpha$ antibody [diluted 1:500 (provided by Prof. Gass mann, University of Zurich)] or rabbit polyclonal anti HO 1 [diluted 1:1000 (Stressgen Bioreagents) followed by a horseradish peroxidase conjugated secondary antibodies [diluted 1:5000 (Promega)]. The signals were detected by enhanced chemiluminescence (LiteAblot ${ }^{\circledR}$ Euroclone, Digitana). The membranes were re incubated with a rabbit polyclonal anti Spl antibody [diluted 1:10,000 (Santa Cruz Biotech nology] or rabbit polyclonal anti $\beta$ actin [diluted 1:5000 (Sigma)] to control for protein loading.

\section{6. $R N A$ extraction and real-time $R T-P C R$}

Total RNA was isolated from hepatic tissue using Trizol in accor dance with the manufacturer's instructions (Life Technologies). One microgram of total RNA was then treated with DNAse for $30 \mathrm{~min}$ at $37^{\circ} \mathrm{C}$. Reverse transcription was performed using the Omniscript RT kit (Qiagen) and random primers (Promega). Real time PCR for murine erythropoietin (Epo), vascular endothelial cell growth factor (VEGF), hepatocyte growth factor (HGF), heme oxygenase (HO) 1, A20, interleukin (IL) 6, insulin like growth factor binding protein (IGFBP) 1 and HIF $1 \alpha$ was performed using the ABI Prism 7700 Sequence Detection System, the Taqman universal PCR Master Mix, and assay on demand probes and primers (Applied Biosystems, Rotk reuz, $\mathrm{CH}$ ) according to standard protocols. Parameters for baseline and threshold cycle $\left(C_{\mathrm{t}}\right)$ settings were kept constant for each gene. To calculate $\Delta C_{\mathrm{t}}$, the $C_{\mathrm{t}}$ value for each target gene was standardized against that for the internal ribosomal RNA (18S) control probe. $\Delta \Delta C_{\mathrm{t}}$ values were calculated by subtracting the $\Delta C_{\mathrm{t}}$ values for HA clamped mice from the mean $\Delta C_{\mathrm{t}}$ value for the sham operated controls. Rela tive fold increases were calculated using the formula $2^{-\Delta \Delta C_{\mathrm{t}}}$.

\subsection{Caspase-3 assay}

Hundred microgram of protein from liver tissue lysates was re sus pended in a volume of $20 \mu \mathrm{l}$ and combined with $32 \mu \mathrm{l}$ of caspase assay buffer [312.5 mM HEPES (pH 7.5), 0.3\% Chaps, 3.1\% sucrose], $2 \mu$ of DMSO, $1 \mu \mathrm{l}$ of $1 \mathrm{M}$ DTT, $60 \mu \mathrm{l}$ of water and $1 \mathrm{ml}$ of $100 \mu \mathrm{M}$ synthetic DEVD amc caspase 3 substrate in DMSO (Calbiochem). The fluores cence emission at $30^{\circ} \mathrm{C}$ was monitored kinetically over a 50 minute period using a Spectramax Gemini Fluorometer (Molecular Devices).

\subsection{Statistics}

The statistical analysis was performed using the SPSS 11.5 pro gramme. The tests implemented are specified in the figure legends. Sta tistical significance was set at $p<0.05$.

\section{Results}

\subsection{Clamping of the hepatic artery decreases tissue oxygenation without causing immediate liver cell damage}

To induce hypoxic stress within the livers of normal $\mathrm{Balb} / \mathrm{C}$ mice, the HA was clamped for $2 \mathrm{~h}$. The period of two hours was chosen because previously we observed HIF-1 $\alpha$ protein stabilization in the livers of mice subjected for $12 \mathrm{~h}$ to normobaric systemic hypoxia [21]. During the first $30 \mathrm{~min}$ of clamping, the hepatic oxygen saturation dropped to less than $50 \%$ of the baseline value, and was sustained for the duration of the experiment (Fig. 1a). The decrease in liver oxygenation was further confirmed by injecting the mice with HypoxyProbe ${ }^{\mathrm{TM}}-1$ (pimonidazole hydrochloride)
$30 \mathrm{~min}$ before the end of the experiment. At low oxygen levels, HypoxyProbe ${ }^{\mathrm{TM}}-1$ is reductively activated and covalently binds to cellular macromolecules. Since accumulation of the reduced pimonidazole depends solely upon the oxygen tension, its level can be used to gauge changes in tissue oxygenation [22]. As a result, staining for HypoxyProbe ${ }^{\mathrm{TM}}-1$ was more intense in the livers of HA-clamped mice than in those of the sham-operated controls (Fig. 1b).

Tissue metabolism and cellular damage were assessed histologically and by monitoring the interstitial levels of lactate, pyruvate and glycerol. For the purpose of comparison, an anoxic model of complete ischemia to the left liver lobe was used. Histological and chemical analysis revealed increasing signs of hepatic damage and necrosis during $2 \mathrm{~h}$ of complete ischemia but not during $2 \mathrm{~h}$ of HA-clamping (Fig. 2a). Compared to sham-operated controls, neither the lactate:pyruvate ratio, used to measure the metabolic state of the tissue (Fig. 2b), nor the glycerol level, a marker of cell damage (Fig. 2c) of HA-clamped livers changed with time. Both values steadily increased in completely ischemic/anoxic livers indicating an increase in anaerobic metabolism with consecutive cellular disintegration (Fig. $2 \mathrm{~b}$ and c).

\subsection{Deprivation of the arterial blood supply initiates a hypoxia-driven molecular response in the liver}

HIF-1 activation was used as a marker to determine whether clamping of the HA generated a stimulus sufficient to induce a hypoxia-driven molecular response. Analyzed by immunoblot, the oxygen-sensitive $\alpha$-subunit of HIF-1 was not detected within the hepatic nuclear protein extracts derived from sham-operated mice (Fig. 3a, lanes 1 2). Whereas, in HA-clamped animals, HIF-1 $\alpha$ protein was stabilized and present at a high level (Fig. 3a, lanes 3 6). To show that stabilization of HIF-1 $\alpha$ protein led to a transcriptional activation of a target gene, we determined the mRNA level of Epo by real-time RT-PCR. The up-regulation of Epo mRNA is highly sensitive to oxygen availability and it is activated in a HIF-dependent manner [4]. Epo mRNA was not detected within normal hepatic tissue, but it was up-regulated to measurable levels in the liver of HA-clamped animals (Fig. 3b). The mRNA levels of other genes that are targeted by HIF-1 as well as of those with established hepatoprotective properties were also determined. Although the mRNA of the HIF-1 target genes HO-1 and IGFBP-1 were up-regulated 3- and 42-fold, respectively, the mRNA levels for the growth factors, VEGF and HGF did not change. Additionally, the mRNA levels of A20 (3-fold) and IL-6 (12-fold) were increased (Fig. 3c). As expected the mRNA of HIF-1 $\alpha$ did not change as it is primarily regulated post-transcriptionally. An increase of HO-1 and A20 protein was observed in the liver tissue (Fig. $3 c$ and d), whereas a sig- 


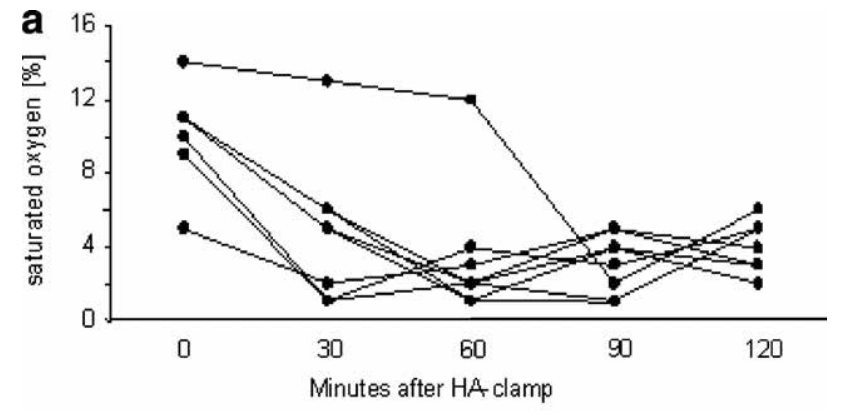

b

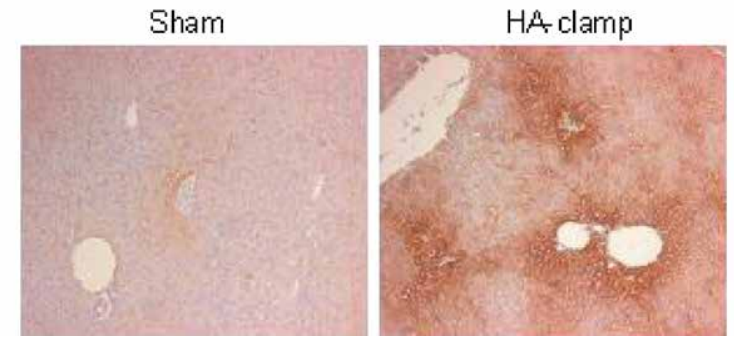

Fig. 1. Interruption of the liver's arterial blood supply induces a hypoxic stress. (a) After clamping the HA, oxygen saturation measurements (filled circles) were taken every $30 \mathrm{~min}$ for $\mathbf{2} \mathrm{h}$. The traces for each of the eight animals are depicted separately. Within $30 \mathrm{~min}$ of HA-clamping, the oxygen-saturation level for each animal dropped significantly below the baseline value $(p<0.01)$ and this reduced tension was sustained at each subsequent sampling time $(30,60,90$ and $120 \mathrm{~min})$. The data were statistically evaluated using ANOVA and Dunnett's multiple comparison test. (b) Thirty minutes before the end of the experiment, mice were injected with HypoxyProbe ${ }^{\top \mathrm{M}}-1$ ( $80 \mathrm{mg} / \mathrm{kg}$ of body weight). Representative images for HA-clamped livers and sham-operated controls immunostained with an antibody against $\mathrm{Hypoxyprobe}^{\mathrm{T} \mathrm{M}}-1$ are shown (final magnification: $100 \times$ ).

nificant increase of secreted proteins, IL-6 and IGFBP-1 was not yet detectable in the serum at this early time point (data not shown). Taken together these data indicate that a temporary deprivation of the liver's arterial blood supply generates a level of hypoxia that suffices to activate the HIF-1 signalling pathway and the up-regulation of hepatoprotective genes.

\subsection{Inhibition of Fas-induced fulminate liver failure in mice by hypoxic preconditioning}

We next questioned whether the molecular response to hypoxic stress in the liver may in part be hepatoprotective. Hepatocytes constitutively express Fas (CD95), and binding of the Fas ligand or injection of the agonistic anti-Fas antibody, Jo2, is a well established model to induce massive hepatocyte apoptosis and liver failure in a time- and dose-dependent manner [23]. Mice were either sham operated or pre-conditioned by clamping the HA. Two hours after injecting Jo2, histological signs of cell damage and apoptosis were greater in the shamoperated than in the animals pre-conditioned by clamping the HA (Fig. 4a). Accordingly, down stream targets of Fas activation namely caspase-3 activation and cleavage of the nuclear membrane protein lamin A were sig- a
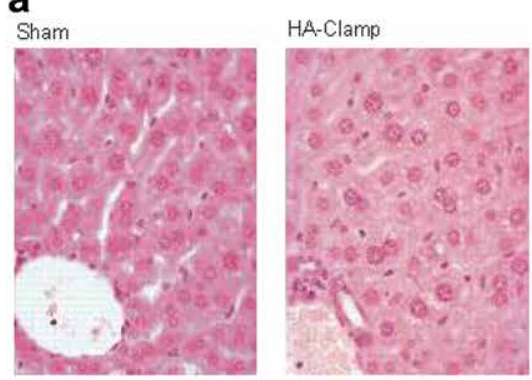

Complete Ischemia

b
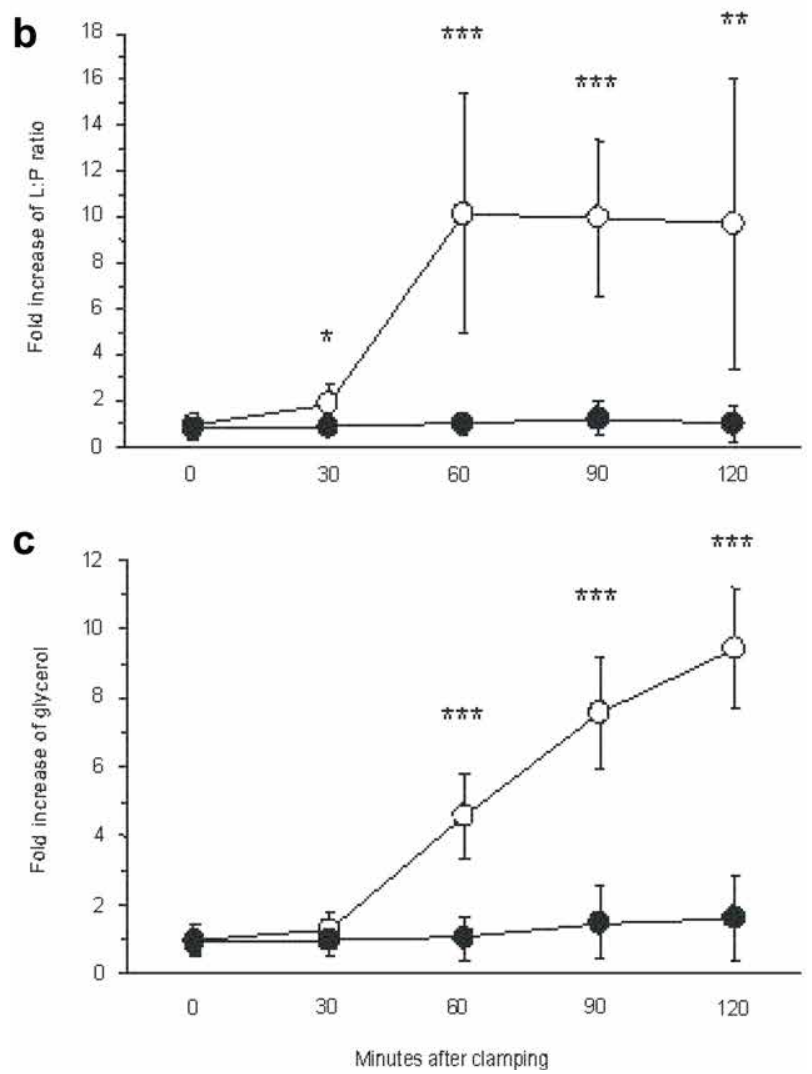

Fig. 2. Temporary interruption of the liver's arterial blood supply causes no tissue damage. (a) Photomicrographs of representative paraffinembedded sections after staining with haematoxylin and eosin (final magnification: $200 \times$ ). Arrows indicate signs of cell damage and ischemic necrosis. (b and c) Interstitial levels of lactate, pyruvate and glycerol were collected by microdialysis $0,30,60,90$ and $120 \mathrm{~min}$ after HAclamping ( $n=8$, filled circles) or total ischemia $(n=6$, open circles). At each time-point, values were normalized to the mean values for shamoperated mice $(n=6)$. (b) The lactate:pyruvate ratio and (c) the glycerol level remained low in both HA-clamped or control livers compared to the significant increase in the ischemic livers. Mean values are represented together with the standard deviation. $* p<0.05 ; * * p<0.01$; $* * * p<0.001$. The data were statistically evaluated using ANOVA and Turkey's test.

nificantly lower in the liver of HA-clamped animals (Fig. $4 \mathrm{a}$ and b). Moreover, the HA-clamped mice treated with Jo2 had a longer median survival time (10.5 h) than sham-operated controls (3.2 h) (Fig. 4c). Remarkably, all of the control mice died within $8 \mathrm{~h}$, whereas, 3 of the 12 HA-clamped animals survived longer than $24 \mathrm{~h}$. 
a
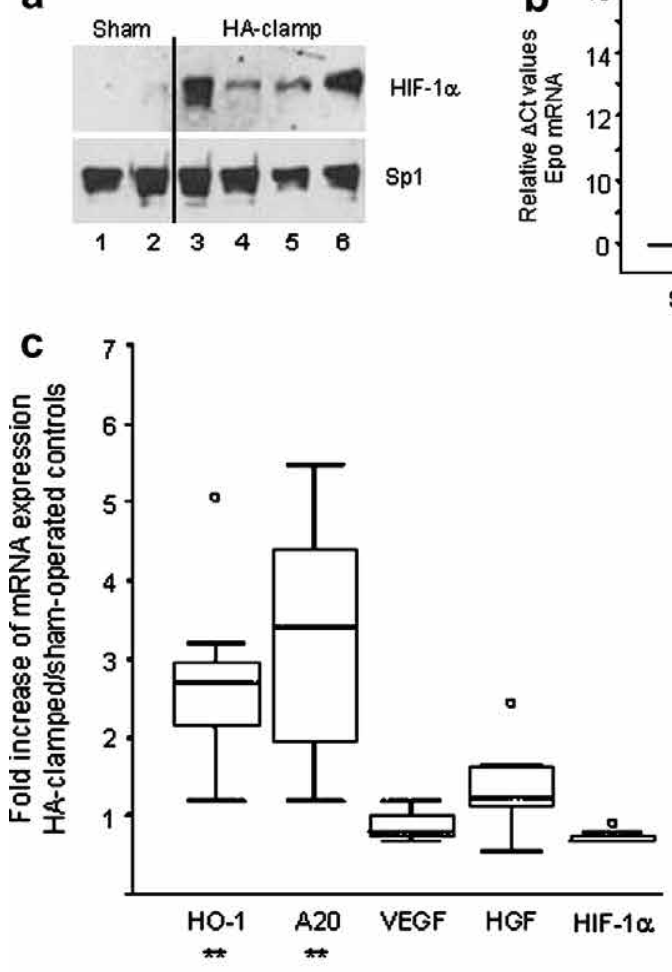

d hypoxia $(n=2) \quad(n=2)$
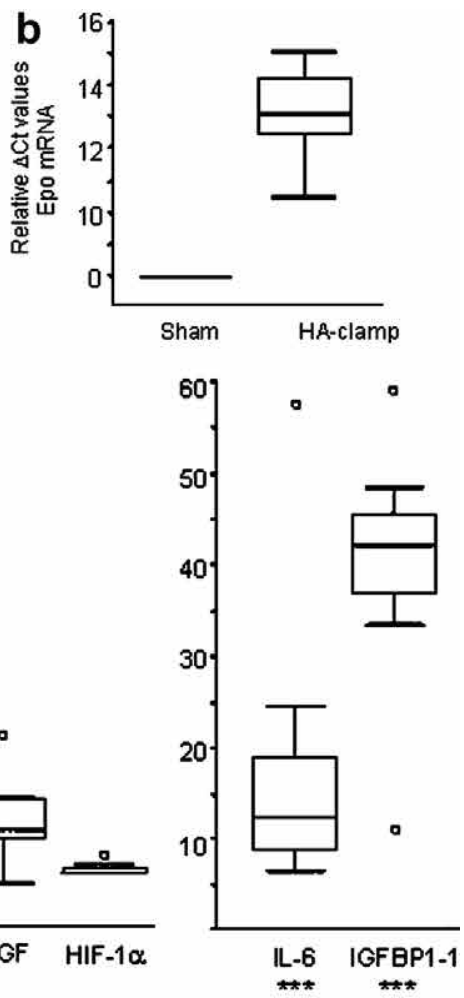

HA-clamping $(n=6)$

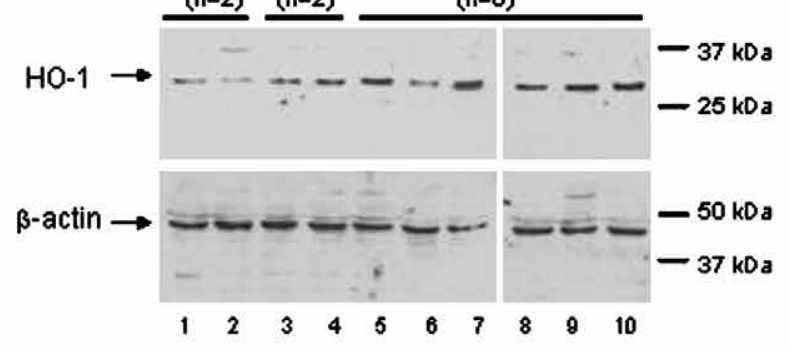

e

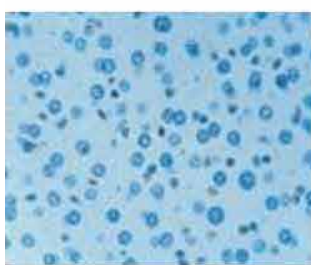

Negative control

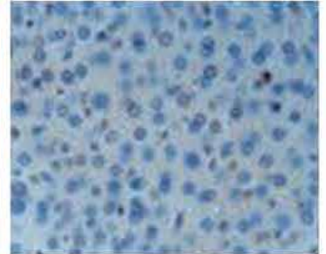

Sham

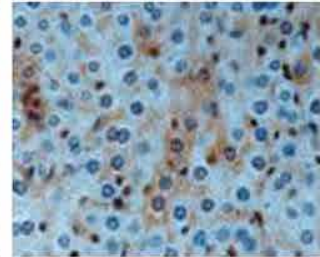

HA-clamp

Fig. 3. Interruption of the liver's arterial blood supply elicits a molecular response. (a) Extracts of hepatic nuclear proteins were separated by SDS PAGE from sham-operated (lanes 1 and 2) and HA-clamped mice (lanes 3 6). Membranes were incubated with either a chicken polyclonal antibody against HIF-1 $\alpha(120 \mathrm{kDA})$ or a rabbit polyclonal antibody against Sp1 $(87 \mathrm{kDa})$, the latter being used to control for nuclear protein loading. (b) The mRNA level of Epo within the livers of HA-clamped mice $(n=7)$ and sham-operated controls $(n=4)$ are represented as relative values. These were obtained by subtracting the $\Delta C_{t}$ s for HA-clamped tissue from 40 (an arbitrary value set for the control mice). (c) The mRNA levels of genes within the livers of HA-clamped mice $(n=7)$ are expressed relative to sham-operated controls $(n=4)$. The median value (boxed line), the interquartile range (height of box), the range (lateral bars) and outliers (open circles) are depicted. $\Delta C_{\mathrm{t}}$ values were used for the statistical analysis $\left(t\right.$-test). ${ }^{*} p<0.05 ; * * p<0.01$; ${ }^{* * *} p<0.001$. (d) Extracts of hepatic proteins were separated by SDS PAGE from sham-operated (lanes 1 and 2) and HA-clamped mice (lanes 5 10). Mice exposed to $6 \% \mathrm{O}_{2}$ were used as a positive control (lanes 3 and 4)(21). Membranes were incubated with either a polyclonal antibody against $\mathrm{HO}-1$ $(32 \mathrm{kDA})$ or an antibody against $\beta$-actin $(42 \mathrm{kDa})$, the latter being used to control for protein loading. Five out of six livers increased $\mathrm{HO}-1 \mathrm{protein}$ after clamping the HA. (e) Photomicrograph shows a representative image of cytoplasmic expression of A20 in the hepatocytes of animals after $2 \mathrm{~h}$ of HAclamping compared to sham operated and no-primary controls (final magnification: $200 \times$ ). 
a

$H \& E$
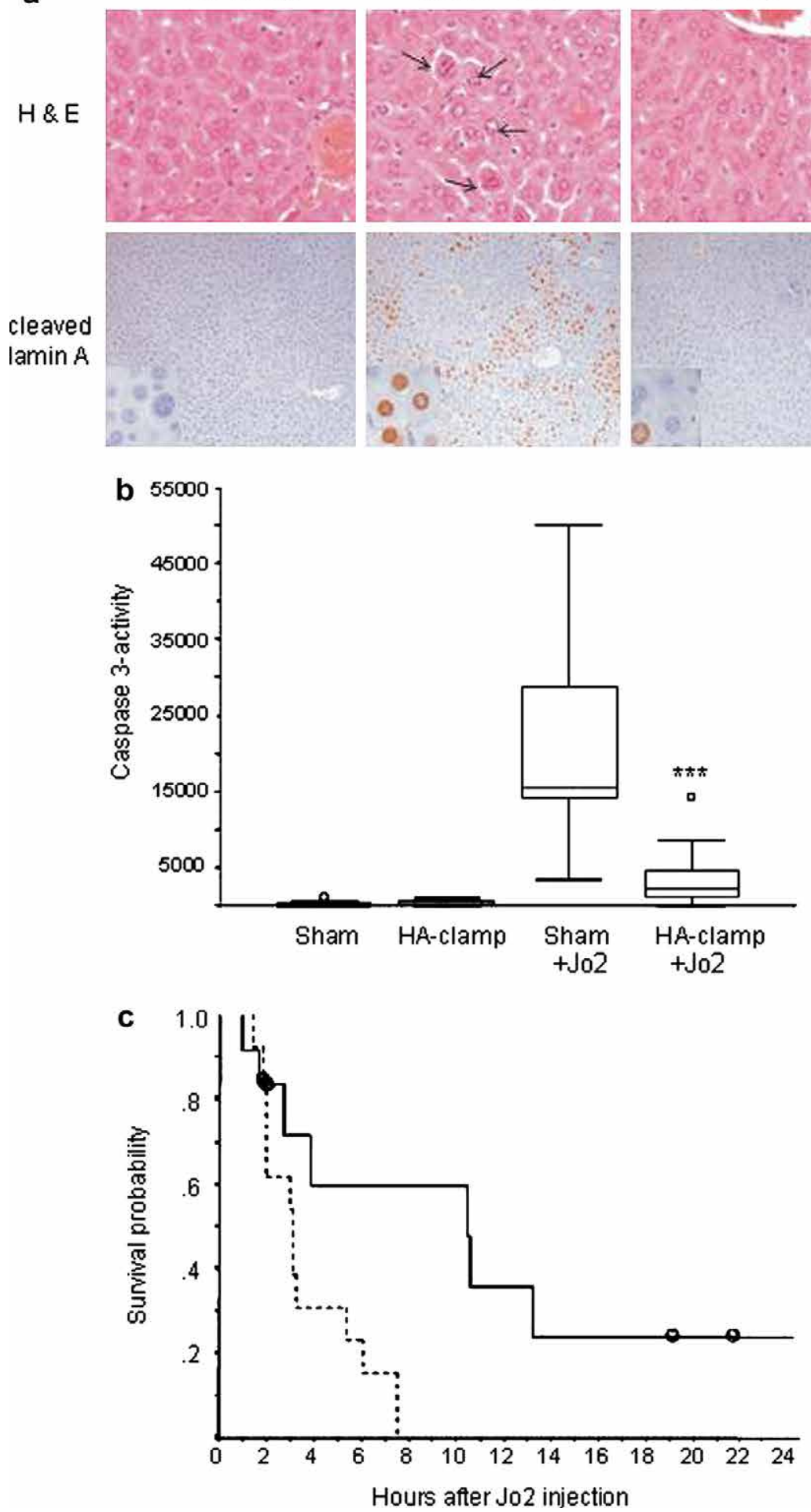

Fig. 4. Pre-conditioning by HA-clamping inhibits Fas-mediated apoptosis and prolongs animal survival. (a) Photomicrographs of representative haematoxylin and eosin stained sections of HA-clamped and sham-operated livers, with or without injection of the anti-Fas antibody, Jo2, (final magnification: 200×). Arrows indicate signs of apoptosis. Tissue sections were immunostained for cleaved lamin A (final magnification: 100 $\times$ ). The insets (magnification: 400 $\times$ ) demonstrate staining of the nuclear membrane. (b) There was no significant difference in caspase-3 activity in sham-operated $(n=11)$ compared to HA-clamped $(n=4)$ livers $\left[v_{\text {max }_{\text {avg }}}=239 \mathrm{vs.} 431 ; p=0.425(t\right.$-test $\left.)\right]$ in mice that were not treated with Jo2. For mice that did receive an injection of the anti-Fas antibody, caspase-3 activity was significantly lower in HA-clamped $(n=12)$ than in sham-operated $(n=11)$ livers $\left[v_{\text {max }_{a v g}}=3637\right.$ vs. $21044 ; \boldsymbol{p}<0.001$ ( $t$-test) $]$. (c) The survival probability of mice that were preconditioned by HA-clamping (solid line, $\left.n=12\right)$ prior to injection Jo2 was significantly higher $[p=0.014$ (Logrank test) $]$ than that of sham-operated controls (dashed line, $n=13)$. Censored animals (open circles, $n=5$ ) in the HA-clamp group were sacrificed for histological analyses. 


\section{Discussion}

In this study we have demonstrated that clamping the hepatic artery while maintaining portal circulation results in a hypoxic stress in the liver without the damaging effects associated with tissue ischemia. In turn, the decrease in oxygen saturation stabilizes HIF-1 $\alpha$ and up-regulates a set of hepatoprotective genes including known HIF-1 target genes such as HO-1 and IGFBP-1, but also genes that are not so far recognized as part of the hypoxic response such as A20 and IL-6. And finally, pre-conditioning the liver by temporarily clamping the HA is able to delay the onset of hepatocyte apoptosis and prolong animal survival in a model of Fas-mediated hepatotoxicity.

Unlike other organs, the liver's dual blood supply offered a unique and novel approach to study the effects of localized hypoxic stress without a complete interruption in the blood supply (ischemia). Ischemic preconditioning models, which used intermittent anoxic stress, have been shown to prevent liver damage induced by reperfusion injuries or by death-receptor-mediated apoptosis [24]. However, contrary to anoxia, longer durations of hypoxia can persist before reaching the critical threshold of irreversible cellular damage. The molecular pathways that sense and respond to a low oxygen are activated in physiologically relevant oxygen concentrations and help cells to survive and to make the necessary metabolic adaptations. In support of this, we observed that severance of the arterial blood supply to the rodent liver is well tolerated for $2 \mathrm{~h}$, and causes no immediate damage therein, either in signs histological damage or of apoptosis. Recently it was documented that intermittent hypoxia conditions endothelial cells and tumor cells to be more resistant to apoptosis and more prone to advance tumor progression [25].

It is well established that the activation of HIF-1 and the up-regulation of its target genes function to promote cell survival and restore tissue homeostasis under hypoxic conditions. With this in mind, we hypothesize that the mechanism in which hepatocyte apoptosis is delayed is that hypoxic stress in the liver results in a molecular response which in part leads to the up-regulation of hepatoprotective genes. Of the genes we examined, IGFBP-1 and HO-1 are both known targets of HIF-1 and have been shown to protect the liver against apoptosis in Fas-mediated and in ischemia-reperfusion models of liver injury [14,16,26 29]. The haematopoietic cytokine, Epo is the first described HIF-1 target gene, and can contribute to cell survival in non-hepatic tissues [30 33]. However its anti-apoptotic role in the liver has yet to be determined. IL-6 and A20 were also significantly increased in the HA-clamped liver tissue. Although IL-6 and A20 can specifically guard against Fas-mediated cell death by establishing critical levels of the anti-apoptotic proteins FLIP, Bcl-2 and Bcl-xL
[17,19,34 36], and by inhibiting caspase- 8 activation and inflammation, which it achieves via blockage of the transcription factor NF- $\mathrm{kB}[3740]$, respectively, this is the first report that describes their up-regulation as part of the hypoxic response in liver tissue. Further studies will need to determine if they are regulated by hypoxia via a HIF-dependent mechanism. Of note, we observed no change in the expression levels of the HIF target genes VEGF and HGF. These findings accord with previous observation relating to the temporal and spatial activation of hypoxia-responsive genes [41], and together with our own observations in which VEGF and HGF mRNA are increased after a longer hypoxic exposure (Stroka, unpublished observations). The specific activation of HIF-1 has been shown to have a protective effect in non-hepatic tissues $[42,43]$. Further studies focusing on the exact contribution of HIF-1 activation in the liver are currently on-going.

The experimental model adopted in this study was able to demonstrate the potency of hypoxic signalling in the liver and in particular on potential beneficial effects of targeting hypoxic signalling pathways. Recently, pre-treatment with hyperbaric oxygen was shown to reduce liver injury after partial hepatectomy and cold storage time [44]. Taken together, further studies that target the activation of the HIF signalling pathway may offer attractive and clinically implemental approaches whereby the liver can be guarded against injuries that target the activation of death-signalling pathways.

\section{Acknowledgements}

The authors thank Cynthia Furer and Beatrice Zumkehr for their excellent technical assistance, Oliver Baum for his critical reading of the manuscript and Markus Trochsler for his scientific input.

\section{References}

[1] Jungermann K, Kietzmann T. Oxygen: modulator of metabolic zonation and disease of the liver. Hepatology 2000;31:255 260.

[2] Rosmorduc O, Wendum D, Corpechot C, Galy B, Sebbagh N, Raleigh J, et al. Hepatocellular hypoxia induced vascular endo thelial growth factor expression and angiogenesis in experimental biliary cirrhosis. Am J Pathol 1999;155:1065 1073.

[3] Cummins EP, Taylor CT. Hypoxia responsive transcription factors. Pflugers Arch 2005;450:363 371.

[4] Wang GL, Semenza GL. Characterization of hypoxia inducible factor 1 and regulation of DNA binding activity by hypoxia. J Biol Chem 1993;268:21513 21518.

[5] Salceda S, Caro J. Hypoxia inducible factor 1alpha (HIF 1 $\alpha$ ) protein is rapidly degraded by the ubiquitin proteasome system under normoxic conditions. Its stabilization by hypoxia depends on redox induced changes. J Biol Chem 1997;272:22642 22647.

[6] Huang LE, Gu J, Schau M, Bunn HF. Regulation of hypoxia inducible factor $1 \alpha$ is mediated by an $\mathrm{O}_{2}$ dependent degradation domain via the ubiquitin proteasome pathway. Proc Natl Acad Sci USA 1998;95:7987 7992. 
[7] Maxwell PH, Wiesener MS, Chang GW, Clifford SC, Vaux EC, Cockman ME, et al. The tumour suppressor protein VHL targets hypoxia inducible factors for oxygen dependent proteolysis. Nature 1999;399:271 275.

[8] Ohh M, Kaelin Jr WG. The von Hippel Lindau tumour suppres sor protein: new perspectives. Mol Med Today 1999;5:257 263.

[9] Ivan M, Kondo K, Yang H, Kim W, Valiando J, Ohh M, et al. HIF $\alpha$ targeted for VHL mediated destruction by proline hydrox ylation: implications for $\mathrm{O}_{2}$ sensing. Science 2001;292:464 468 .

[10] Jaakkola P, Mole DR, Tian YM, Wilson MI, Gielbert J, Gaskell SJ, et al. Targeting of HIF $\alpha$ to the von Hippel Lindau ubiqui tylation complex by $\mathrm{O}_{2}$ regulated prolyl hydroxylation. Science 2001;292:468 472.

[11] Yu F, White SB, Zhao Q, Lee FS. HIF $1 \alpha$ binding to VHL is regulated by stimulus sensitive proline hydroxylation. Proc Natl Acad Sci USA 2001;98:9630 9635.

[12] Poellinger L, Johnson RS. HIF 1 and hypoxic response: the plot thickens. Curr Opin Genet Dev 2004;14:81 85.

[13] Lee PJ, Jiang BH, Chin BY, Iyer NV, Alam J, Semenza GL, et al. Hypoxia inducible factor 1 mediates transcriptional activation of the heme oxygenase 1 gene in response to hypoxia. J Biol Chem 1997;272:5375 5381

[14] Ke B, Buelow R, Shen XD, Melinek J, Amersi F, Gao F, et al. Heme oxygenase 1 gene transfer prevents CD95/Fas ligand mediated apoptosis and improves liver allograft survival via carbon monoxide signaling pathway. Hum Gene Ther 2002;13:1189 1199 .

[15] Tazuke SI, Mazure NM, Sugawara J, Carland G, Faessen GH, Suen LF, et al. Hypoxia stimulates insulin like growth factor binding protein 1 (IGFBP 1) gene expression in HepG2 cells: a possible model for IGFBP 1 expression in fetal hypoxia. Proc Natl Acad Sci USA 1998;95:10188 10193.

[16] Leu JI, Crissey MA, Taub R. Massive hepatic apoptosis associated with TGF $\beta 1$ activation after Fas ligand treatment of IGF binding protein 1 deficient mice. $\mathbf{J}$ Clin Invest 2003;111:129 139.

[17] Kovalovich K, Li W, DeAngelis R, Greenbaum LE, Ciliberto G, Taub R. Interleukin 6 protects against Fas mediated death by establishing a critical level of anti apoptotic hepatic proteins FLIP, Bcl 2, and Bcl xL. J Biol Chem 2001;276:26605 26613.

[18] Bansal MB, Kovalovich K, Gupta R, Li W, Agarwal A, Radbill $\mathrm{B}$, et al. Interleukin 6 protects hepatocytes from $\mathrm{CCl}_{4}$ mediated necrosis and apoptosis in mice by reducing MMP 2 expression. $\mathbf{J}$ Hepatol 2005;42:548 556.

[19] Wuestefeld T, Klein C, Streetz KL, Betz U, Lauber J, Buer J, et al. Interleukin 6/glycoprotein 130 dependent pathways are protective during liver regeneration. J Biol Chem 2003;278:11281 11288.

[20] Contaldo C, Plock J, Djonov V, Leunig M, Banic A, Erni D. The influence of trauma and ischemia on carbohydrate metabolites monitored in hamster flap tissue. Anesth Analg 2005;100:817 822.

[21] Stroka DM, Burkhardt T, Desbaillets I, Wenger RH, Neil DA, Bauer C, et al. HIF 1 is expressed in normoxic tissue and displays an organ specific regulation under systemic hypoxia. FASEB $\mathbf{J}$ 2001;15:2445 2453 .

[22] Arteel GE, Thurman RG, Yates JM, Raleigh JA. Evidence that hypoxia markers detect oxygen gradients in liver: pimonidazole and retrograde perfusion of rat liver. Br J Cancer 1995;72:889 895.

[23] Ogasawara J, Watanabe Fukunaga R, Adachi M, Matsuzawa A, Kasugai T, Kitamura $\mathrm{Y}$, et al. Lethal effect of the anti Fas antibody in mice. Nature 1993;364:806 809.

[24] Selzner N, Rudiger H, Graf R, Clavien PA. Protective strategies against ischemic injury of the liver. Gastroenterology 2003;125:917 936

[25] Martinive P, Defresne F, Bouzin C, Saliez J, Lair F, Gregoire V, et al. Preconditioning of the tumor vasculature and tumor cells by intermittent hypoxia: implications for anticancer therapies. Can cer Res 2006;66:11736 11744 .
[26] Leu JI, Crissey MA, Craig LE, Taub R. Impaired hepatocyte DNA synthetic response posthepatectomy in insulin like growth factor binding protein 1 deficient mice with defects in C/EBP beta and mitogen activated protein kinase/extracellular signal regu lated kinase regulation. Mol Cell Biol 2003;23:1251 1259.

[27] Amersi F, Buelow R, Kato H, Ke B, Coito AJ, Shen XD, et al. Upregulation of heme oxygenase 1 protects genetically fat Zucker rat livers from ischemia/reperfusion injury. $\mathbf{J}$ Clin Invest 1999;104:1631 1639

[28] Lai IR, Ma MC, Chen CF, Chang KJ. The protective role of heme oxygenase 1 on the liver after hypoxic preconditioning in rats. Transplantation 2004;77:1004 1008.

[29] Redaelli CA, Tian YH, Schaffner T, Ledermann M, Baer HU, Dufour JF. Extended preservation of rat liver graft by induction of heme oxygenase 1. Hepatology 2002;35:1082 1092.

[30] Parsa CJ, Matsumoto A, Kim J, Riel RU, Pascal LS, Walton GB, et al. A novel protective effect of erythropoietin in the infarcted heart. J Clin Invest 2003;112:999 1007.

[31] Brines ML, Ghezzi P, Keenan S, Agnello D, de Lanerolle NC, Cerami C, et al. Erythropoietin crosses the blood brain barrier to protect against experimental brain injury. Proc Natl Acad Sci USA 2000;97:10526 10531.

[32] Grimm C, Wenzel A, Groszer M, Mayser H, Seeliger M, Samardzija M, et al. HIF 1 induced erythropoietin in the hypoxic retina protects against light induced retinal degeneration. Nat Med 2002;8:718 724

[33] Cai Z, Manalo DJ, Wei G, Rodriguez ER, Fox Talbot K, Lu H, et al. Hearts from rodents exposed to intermittent hypoxia or erythropoietin are protected against ischemia reperfusion injury. Circulation 2003;108:79 85.

[34] Kovalovich K, DeAngelis RA, Li W, Furth EE, Ciliberto G, Taub $\mathrm{R}$. Increased toxin induced liver injury and fibrosis in interleukin 6 deficient mice. Hepatology 2000;31:149 159.

[35] Streetz KL, Tacke F, Leifeld L, Wustefeld T, Graw A, Klein C, et al. Interleukin 6/gp130 dependent pathways are protective during chronic liver diseases. Hepatology 2003;38:218 229.

[36] Streetz KL, Wustefeld T, Klein C, Kallen KJ, Tronche F, Betz UA, et al. Lack of gp130 expression in hepatocytes promotes liver injury. Gastroenterology 2003;125:532 543.

[37] Cooper JT, Stroka DM, Brostjan C, Palmetshofer A, Bach FH, Ferran C. A20 blocks endothelial cell activation through a NF кB dependent mechanism. J Biol Chem 1996;271:18068 18073.

[38] Arvelo MB, Cooper JT, Longo C, Daniel S, Grey ST, Mahiou J, et al. A20 protects mice from D galactosamine/lipopolysaccharide acute toxic lethal hepatitis. Hepatology 2002:35:535 543.

[39] Daniel S, Arvelo MB, Patel VI, Longo CR, Shrikhande G, Shukri $\mathrm{T}$, et al. A20 protects endothelial cells from TNF , Fas , and NK mediated cell death by inhibiting caspase 8 activation. Blood 2004; 104:2376 2384 .

[40] Longo CR, Patel VI, Shrikhande GV, Scali ST, Csizmadia E, Daniel S, et al. A20 protects mice from lethal radical hepatectomy by promoting hepatocyte proliferation via a p21wafl dependent mechanism. Hepatology 2005;42:156 164.

[41] Denko NC, Fontana LA, Hudson KM, Sutphin PD, Raychaudh uri S, Altman R, et al. Investigating hypoxic tumor physiology through gene expression patterns. Oncogene 2003;22:5907 5914.

[42] Maloyan A, Eli Berchoer L, Semenza GL, Gerstenblith G, Stern MD, Horowitz M. HIF $1 \alpha$ targeted pathways are activated by heat acclimation and contribute to acclimation ischemic cross tolerance in the heart. Physiol Genomics 2005;23:79 88.

[43] Karhausen J, Furuta GT, Tomaszewski JE, Johnson RS, Colgan SP, Haase VH. Epithelial hypoxia inducible factor 1 is protective in murine experimental colitis. J Clin Invest 2004;114:1098 1106.

[44] Ijichi H, Taketomi A, Yoshizumi T, Uchiyama H, Yonemura Y, Soejima $Y$, et al. Hyperbaric oxygen induces vascular endothelial growth factor and reduces liver injury in regenerating rat liver after partial hepatectomy. J Hepatol 2006;45:28 34. 